\title{
RADIOCARBON CALIBRATION FOR JAPANESE WOOD SAMPLES
}

\author{
Minoru Sakamoto ${ }^{1}$ - Mineo Imamura ${ }^{1,2} \bullet$ Johannes van der Plicht ${ }^{3} \bullet$ Takumi Mitsutani $^{4} \bullet$ \\ Makoto Sahara ${ }^{1,5}$
}

ABSTRACT. The radiocarbon content of Japanese cedars was measured by accelerator mass spectrometry for decadal treering samples from the period of $240 \mathrm{BC}$ to AD 900. Conventional gas counting was also used for part of the samples. The data were compared with the INTCAL98 calibration curve (Stuiver et al. 1998). The results indicate that the difference in atmospheric ${ }^{14} \mathrm{C}$ between Japan and North America or Europe is negligible at this period, less than $18{ }^{14} \mathrm{C}$ yr using an average of 50 yr. However, in the period of about AD 100 to about AD 200, we cannot exclude the possibility of a deviation of the order of 30 to $40{ }^{14} \mathrm{C}$ yr to the older ages.

\section{INTRODUCTION}

Precise calibration data are available for the atmospheric ${ }^{14} \mathrm{C}$ record of the past, enabling us to estimate true ages with much more confidence than before. The combination of ${ }^{14} \mathrm{C}$ dates and dendrochronology can lead to an exact age determination. Moreover, accurate dates - up to about 10-20 calibrated $\mathrm{yr}$ - can be obtained by means of the so-called wiggle-matching technique. Therefore, precise dating by ${ }^{14} \mathrm{C}$ is of increasing interest for archaeologists. Precise knowledge on the local effect of the atmospheric ${ }^{14} \mathrm{C}$ content is becoming more important for future perspectives of precise ${ }^{14} \mathrm{C}$ dating.

Thus far, conversion of ${ }^{14} \mathrm{C}$ dates to calendar yr has been based on ${ }^{14} \mathrm{C}$ calibration curves obtained from North American and European trees for Japanese samples. No calibration curve for Asian trees is available. It is important to examine possible regional deviation from INTCAL98 and investigate the extent of the regional effect in ${ }^{14} \mathrm{C}$ calibration. By doing this, we can safely apply the INTCAL98 calibration curve to the Japanese samples. The aim of this research is to obtain precise ${ }^{14} \mathrm{C}$ dates for dendrochronologically-dated woods, particularly for the Yayoi and Kofun periods, which are described below.

For archaeological research in Japan, the period of several centuries around AD 1 has been of great interest because in this period rapid changes took place in many cultural and social aspects. The first half of the period corresponds to the prehistoric era (Yayoi period, 4th century BC to 3rd century $\mathrm{AD})$ during which paddy rice farming has spread over the islands and the use of bronze and iron started. The latter half corresponds to the protohistoric era (Kofun period, 3rd century AD to 6th century AD), which is characterized by huge burial mounds and the establishment of the first state in Japan. It is also conceived that cultural exchange was quite active between the East Asian continent and the Japanese archipelago. The absolute chronology of these periods is controversial, since recent dendrochronological dates obtained for several Yayoi archaeological sites show a significant discrepancy from the archaeological chronology that had been widely accepted (Mitsutani 2002). Therefore, precise dating has been of great concern for many archaeologists in Japan as well. Recent studies show that ${ }^{14} \mathrm{C}$ dating within a few tens of yr is possible using the wiggle-matching technique, as mentioned above. The use of the universal calibration curves for Japanese wood samples should be suitable for practical use, however, it is necessary to prove that the curves are correct.

\footnotetext{
${ }^{1}$ National Museum of Japanese History, 117 Jonai-cho, Sakura-shi, Chiba 285-8502, Japan.

Email: sakamoto@rekihaku.ac.jp.

${ }^{2}$ Department of Japanese History, Graduate University for Advanced Studies, 117 Jonai-cho, Sakura-shi, Chiba 285-8502, Japan.

${ }^{3}$ Center for Isotope Research, University of Groningen, NL-9747 AG Groningen, the Netherlands.

${ }^{4}$ Nara National Cultural Properties Research Institute, 2-9-1 Nijo-cho, Nara-shi, Nara 630-8002, Japan.

${ }^{5}$ Deceased July 10, 2002.
} 
We have measured the ${ }^{14} \mathrm{C}$ dates of decadal tree rings using 4 Japanese wood specimens that have been dendro-dated. By comparing ${ }^{14} \mathrm{C}$ dates with the INTCAL98 calibration curve, we discuss in detail the applicability of INTCAL98 to the precise ${ }^{14} \mathrm{C}$ dating of the pre- and proto-historic periods in Japan. This produces the first contribution to a calibration curve for Japan. Because of the limited amount of wood available, most of the measurements were done by AMS. Eleven measurements were done by the conventional method.

\section{DESCRIPTIVE BACKGROUND}

\section{Sample source and tree-ring dating}

Four Japanese cedar (Cyptomeria japonica) specimens-HK, MT, AH1, and AH3-were selected for this study. HK was a bogwood unearthed at Hakone, Kanagawa Prefecture, central Honshu Island located about $100 \mathrm{~km}$ west of Tokyo. The ring patterns of HK spanned $453 \mathrm{yr}$. MT was also a bogwood unearthed at Miyata-mura village, Nagano Prefecture, central Honshu Island, with total ring patterns of $372 \mathrm{yr}$. AH1 and $\mathrm{AH} 3$ were individual piles excavated at the Hotta-no-saku archaeological site in Akita Prefecture, northern Honshu Island. The locations of these samples are shown in Figure 1.

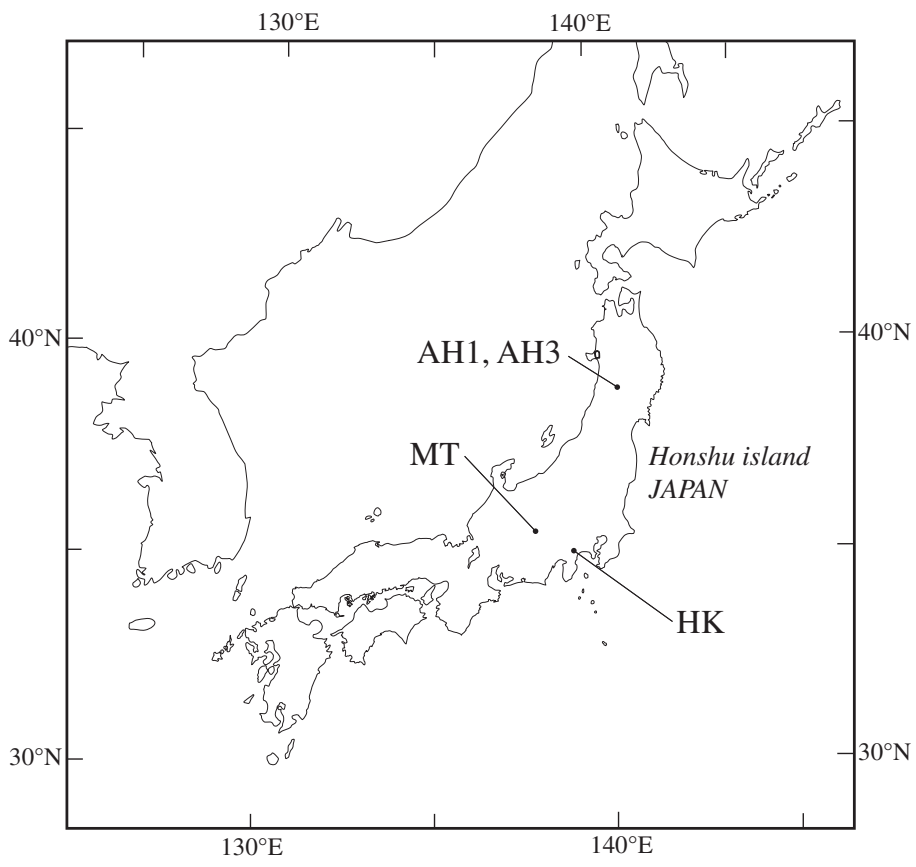

Figure 1 Map of sample locations

Dendrochronological determination of the absolute age for these specimens was performed by comparing the standardized ring patterns with the master chronology for Japanese cedar developed by the Nara National Culture Properties Research Institute (1990). A master standard chronology for a Japanese cedar has been established for tree-ring ages back to $1313 \mathrm{BC}$.

Each specimen was cut into decadal pieces according to its dendro-date. Although the ring width varied, we assumed that each decadal piece represents the mean ${ }^{14} \mathrm{C}$ concentration in that time 
period. Thirty-two samples were obtained from HK corresponding to the age of $240 \mathrm{BC}$ to AD 200, 30 samples from MT (AD 331 to AD 630), 11 samples from AH1 (AD 692 to AD 801), and 24 samples from AH3 (AD 661 to AD 900), respectively. Preliminary measurement using the HK specimen for $201 \mathrm{BC}$ to AD 60 was reported by Imamura et al. (1998).

The surface portion of the sample was removed to prevent possible contamination with modern carbon, and each decadal sample piece was pulverized into fine fiber tips of about $0.1 \times 1 \mathrm{~mm}$ size using a mill (an electric blender).

\section{${ }^{14} \mathrm{C}$ measurements}

\section{Accelerator Mass Spectrometry (AMS) (lab. code GrA)}

The HK, MT, and AH3 samples were measured for ${ }^{14} \mathrm{C}$ using AMS. About $100 \mathrm{mg}$ of the sample fiber was treated by acid-alkali-acid (in each step, the sample was reacted 5 times with $1.2 \mathrm{~N} \mathrm{HCl}$ or $1.2 \mathrm{~N} \mathrm{NaOH}$ for $1 \mathrm{hr}$ ), followed by removal of lignin with $\mathrm{Cl}_{2}$ (using $\mathrm{NaClO}_{2}$ and $\mathrm{HCl}$ ) and most $\beta$ and $\gamma$ - cellulose with a $17.5 \% \mathrm{NaOH}$ solution. The purified sample, mainly consisting of $\alpha$-cellulose, was then neutralized, washed with pure $\mathrm{H}_{2} \mathrm{O}$, filtrated, and dried.

Several $\mathrm{mg}$ of cellulose were taken in a Vycor-glass tube together with few hundred $\mathrm{mg}$ of $\mathrm{CuO}$ (organic carbon analysis grade: Wako Chemical Co.) and sealed off from the vacuum system. The sample tube was then heated at $850{ }^{\circ} \mathrm{C}$ for $2 \mathrm{hr}$ to completely oxidize the cellulose. The obtained $\mathrm{CO}_{2}$ was transferred to the high-vacuum $\mathrm{CO}_{2}$ purification systems (at the National Museum of Japanese History for $\mathrm{HK}$ and $\mathrm{AH} 3$, and at the University of Groningen for MT) and purified cryogenically. The pressure of the purified $\mathrm{CO}_{2}$ was measured by a gauge and divided into 2 breakseals. Graphite targets were prepared in Groningen and the ${ }^{14} \mathrm{C} /{ }^{12} \mathrm{C}$ and ${ }^{13} \mathrm{C} /{ }^{12} \mathrm{C}$ ratios were measured with the Groningen HVEE AMS system (van der Plicht et al. 2000). ${ }^{14} \mathrm{C}$ dates were determined from the ${ }^{14} \mathrm{C} /{ }^{12} \mathrm{C}$ ratios after normalizing the isotopic ratio of ${ }^{13} \mathrm{C} /{ }^{12} \mathrm{C}$ to $\delta^{13} \mathrm{C}=-25.0$ per mil.

\section{Conventional ${ }^{14} \mathrm{C}$ measurements (lab. code $\mathrm{GrN}$ )}

The AH1 samples were measured for ${ }^{14} \mathrm{C}$ in the Groningen conventional laboratory. Several $\mathrm{g}$ of the sample fiber were treated by the acid-alkali-acid method. Treated fiber was combusted into $\mathrm{CO}_{2}$ and purified. Obtained $\mathrm{CO}_{2}$ was collected in a metal cylinder, introduced into a proportional counter, and measured for ${ }^{14} \mathrm{C} \beta$-rays radiation (Mook and Streurman 1983; van der Plicht et al. 1992). Also, here the ${ }^{14} \mathrm{C}$ dates are reported including a correction for fractionation to $\delta^{13} \mathrm{C}=-25.0$ per mil.

\section{DISCUSSION}

The results of the ${ }^{14} \mathrm{C}$ measurements for each sample specimen are shown in Tables 2-5. The data include our preliminary report on the 200-60 BC samples for HK (Imamura et al. 1998). The errors include the statistics of the ${ }^{14} \mathrm{C}$ counts and uncertainties in the ${ }^{13} \mathrm{C} /{ }^{12} \mathrm{C}$ and ${ }^{14} \mathrm{C} /{ }^{12} \mathrm{C}$ ratios of the standard and blank targets. The extent of modern carbon contamination was of the order of $0.1 \%$ or less, which is negligible. Uncertainties of original ${ }^{14} \mathrm{C}$ standards are not included. In Figure 2, the results are compared with the calibration curve of INTCAL98 (Stuiver et al. 1998). Error bars represent a $68 \%(1 \sigma)$ uncertainty.

From the data plotted in Figure 2, it is shown that almost all the data are in good agreement (within $2 \sigma$ ) with the INTCAL98 calibration curve. There may be an exception in the period of around AD 100-200, which may show a significant deviation toward the older ages and will be discussed later in more detail. 


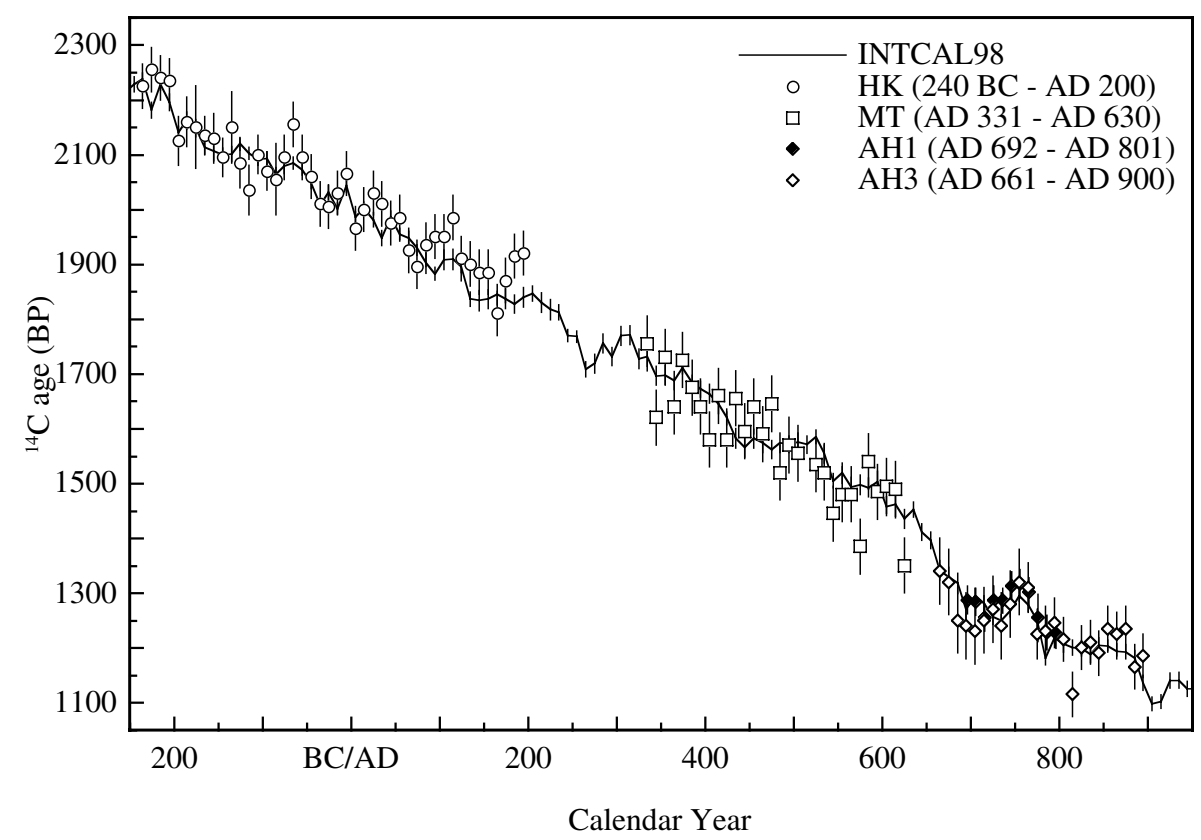

Figure $2{ }^{14} \mathrm{C}$ data for Japanese cedars compared with INTCAL98

Table 1 Source of the tree-ring sample specimens

\begin{tabular}{lllll}
\hline Sample code & Locality & Latitude & Longitude & Tree-ring age \\
\hline HK & $\begin{array}{l}\text { Hakone-machi Town, central } \\
\text { Honshu Island, Japan }\end{array}$ & $35^{\circ} 10^{\prime} \mathrm{N}$ & $139^{\circ} 05^{\prime} \mathrm{E}$ & $240 \mathrm{BC}-\mathrm{AD} 200$ \\
MT & $\begin{array}{l}\text { Miyata-mura Village, central } \\
\text { Honshu Island, Japan }\end{array}$ & $35^{\circ} 45^{\prime} \mathrm{N}$ & $137^{\circ} 55^{\prime} \mathrm{E}$ & $\mathrm{AD} 331-\mathrm{AD} 630$ \\
$\mathrm{AH} 1$ & $\begin{array}{l}\text { Hotta-no-saku archaeological site, } \\
\text { northern Honshu Island, Japan }\end{array}$ & $39^{\circ} 30^{\prime} \mathrm{N}$ & $140^{\circ} 35^{\prime} \mathrm{E}$ & $\mathrm{AD} 692-\mathrm{AD} 801$ \\
$\mathrm{AH3}$ & $\begin{array}{l}\text { Hotta-no-saku archaeological site, } \\
\text { northern Honshu Island, Japan }\end{array}$ & $39^{\circ} 30^{\prime} \mathrm{N}$ & $140^{\circ} 35^{\prime} \mathrm{E}$ & $\mathrm{AD} 661-\mathrm{AD} 900$ \\
\hline
\end{tabular}

The significance of deviation for each datum from the INTCAL98 can be given by the formula:

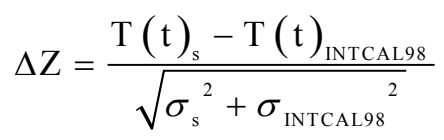

where $\Delta \mathrm{Z}$ is the normalized difference, $T(t)_{S}$ and $T(t)_{I N T C A L 98}$ are the ${ }^{14} \mathrm{C}$ ages of the decadal tree-ring sample and the corresponding INTCAL98 curve for a calibrated age, $t$, and $\sigma_{\mathrm{s}}, \sigma_{\text {INTCAL98 }}$ are their respective uncertainties. The $\Delta Z$ values are calculated for the individual dataset of each specimen. The distribution of cases is plotted in Figure 3 as a function of $\Delta Z$. The total number of the case is normalized to 1 . Figure 3 shows the distribution for each sample specimen is nearly a typical normal distribution and the average of the distribution is very close to zero. This is what is expected when there are no biases in the measurements and no significant regional effect for the whole period investigated. By calculating a best fit to a normal distribution, the shifts are calculated to be $0.42,-0.23$, 
Table 2 Results of ${ }^{14} \mathrm{C}$ measurements (AMS) for the HK series

\begin{tabular}{|c|c|c|c|}
\hline Lab. Code & Sample name & Tree-ring age & ${ }^{14} \mathrm{C}$ age $(\mathrm{BP})$ \\
\hline GrA-14700 & HK-235B & $240 \mathrm{BC}-231 \mathrm{BC}$ & $2225 \pm 40$ \\
\hline GrA-14702 & HK-225B & $230 \mathrm{BC}-221 \mathrm{BC}$ & $2255 \pm 40$ \\
\hline GrA-14703 & HK-215B & $220 \mathrm{BC}-211 \mathrm{BC}$ & $2240 \pm 40$ \\
\hline GrA-14704 & HK-205B & $210 \mathrm{BC}-201 \mathrm{BC}$ & $2235 \pm 40$ \\
\hline GrA-9332 & HK-195B & $200 \mathrm{BC}-191 \mathrm{BC}$ & $2125 \pm 45$ \\
\hline GrA-9326 & HK-185B & $190 \mathrm{BC}-181 \mathrm{BC}$ & $2160 \pm 45$ \\
\hline GrA-8085 & HK-175B & $180 \mathrm{BC}-171 \mathrm{BC}$ & $2150 \pm 75$ \\
\hline GrA-9323 & HK-165B & $170 \mathrm{BC}-161 \mathrm{BC}$ & $2090 \pm 45$ \\
\hline GrA-9330 & HK-165B & $170 \mathrm{BC}-161 \mathrm{BC}$ & $2180 \pm 45$ \\
\hline GrA-9328 & HK-155B & $160 \mathrm{BC}-151 \mathrm{BC}$ & $2130 \pm 45$ \\
\hline GrA-8082 & HK-145B & $150 \mathrm{BC}-141 \mathrm{BC}$ & $2130 \pm 65$ \\
\hline GrA-9419 & HK-145B & $150 \mathrm{BC}-141 \mathrm{BC}$ & $2080 \pm 40$ \\
\hline GrA-8081 & HK-135B & $140 \mathrm{BC}-131 \mathrm{BC}$ & $2150 \pm 65$ \\
\hline GrA-9322 & HK-125B & $130 \mathrm{BC}-121 \mathrm{BC}$ & $2085 \pm 45$ \\
\hline GrA-9327 & HK-115B & $120 \mathrm{BC}-111 \mathrm{BC}$ & $2035 \pm 45$ \\
\hline GrA-9316 & HK-105B & $110 \mathrm{BC}-101 \mathrm{BC}$ & $2080 \pm 45$ \\
\hline GrA-9317 & HK-105B & $110 \mathrm{BC}-101 \mathrm{BC}$ & $2120 \pm 45$ \\
\hline GrA-9318 & HK-095B & $100 \mathrm{BC}-91 \mathrm{BC}$ & $2085 \pm 45$ \\
\hline GrA-9321 & HK-095B & $100 \mathrm{BC}-91 \mathrm{BC}$ & $2050 \pm 45$ \\
\hline GrA-8084 & HK-085B & $90 \mathrm{BC}-81 \mathrm{BC}$ & $2055 \pm 65$ \\
\hline GrA-14705 & HK-075B & $80 \mathrm{BC}-71 \mathrm{BC}$ & $2095 \pm 40$ \\
\hline GrA-14707 & HK-065B & $70 \mathrm{BC}-61 \mathrm{BC}$ & $2155 \pm 40$ \\
\hline GrA-14709 & HK-055B & $60 \mathrm{BC}-51 \mathrm{BC}$ & $2095 \pm 40$ \\
\hline GrA-14689 & HK-045B & $50 \mathrm{BC}-41 \mathrm{BC}$ & $2060 \pm 40$ \\
\hline GrA-14688 & HK-035B & $40 \mathrm{BC}-31 \mathrm{BC}$ & $2010 \pm 40$ \\
\hline GrA-14627 & HK-025B & $30 \mathrm{BC}-21 \mathrm{BC}$ & $2005 \pm 40$ \\
\hline GrA-14628 & HK-015B & $20 \mathrm{BC}-11 \mathrm{BC}$ & $2030 \pm 40$ \\
\hline GrA-14629 & HK-005B & $10 \mathrm{BC}-1 \mathrm{BC}$ & $2065 \pm 40$ \\
\hline GrA-14630 & HK-005A & $\mathrm{AD} 1-\mathrm{AD} 10$ & $1965 \pm 40$ \\
\hline GrA-14632 & HK-015A & $\mathrm{AD} 11-\mathrm{AD} 20$ & $2000 \pm 40$ \\
\hline GrA-14684 & HK-025A & $\mathrm{AD} 21-\mathrm{AD} 30$ & $2030 \pm 40$ \\
\hline GrA-14685 & HK-035A & $\mathrm{AD} 31-\mathrm{AD} 40$ & $2010 \pm 40$ \\
\hline GrA-14690 & HK-045A & $\mathrm{AD} 41-\mathrm{AD} 50$ & $1975 \pm 40$ \\
\hline GrA-14691 & HK-055A & $\mathrm{AD} 51-\mathrm{AD} 60$ & $1985 \pm 40$ \\
\hline GrA-14693 & HK-065A & $\mathrm{AD} 61-\mathrm{AD} 70$ & $1925 \pm 40$ \\
\hline GrA-14694 & HK-075A & $\mathrm{AD} 71-\mathrm{AD} 80$ & $1895 \pm 40$ \\
\hline GrA-14695 & HK-085A & $\mathrm{AD} 81-\mathrm{AD} 90$ & $1935 \pm 40$ \\
\hline GrA-14698 & HK-095A & AD $91-$ AD 100 & $1950 \pm 40$ \\
\hline GrA-14699 & HK-105A & AD $101-$ AD 110 & $1950 \pm 40$ \\
\hline GrA-14710 & HK-115A & AD $111-$ AD 120 & $1985 \pm 40$ \\
\hline GrA-14712 & $\mathrm{HK}-125 \mathrm{~A}$ & AD $121-$ AD 130 & $1910 \pm 40$ \\
\hline GrA-14713 & HK-135A & AD $131-$ AD 140 & $1900 \pm 40$ \\
\hline GrA-14714 & HK-145A & AD $141-$ AD 150 & $1885 \pm 40$ \\
\hline GrA-14715 & HK-155A & AD $151-$ AD 160 & $1885 \pm 40$ \\
\hline GrA-14717 & HK-165A & AD $161-$ AD 170 & $1810 \pm 40$ \\
\hline GrA-14718 & HK-175A & AD $171-$ AD 180 & $1870 \pm 40$ \\
\hline GrA-14720 & HK-185A & AD $181-$ AD 190 & $1915 \pm 40$ \\
\hline GrA-14722 & HK-195A & AD $191-$ AD 200 & $1920 \pm 40$ \\
\hline
\end{tabular}


Table 3 Results of ${ }^{14} \mathrm{C}$ measurements (AMS) for the MT series

\begin{tabular}{llll}
\hline Lab. code & Sample name & Tree-ring age & ${ }^{14}$ C age (BP) \\
\hline GrA-15263 & MT-335 & AD 331 - AD 340 & $1755 \pm 50$ \\
GrA-15264 & MT-345 & AD 341 - AD 350 & $1620 \pm 50$ \\
GrA-15265 & MT-355 & AD 351 - AD 360 & $1730 \pm 50$ \\
GrA-15266 & MT-365 & AD 361 - AD 370 & $1640 \pm 50$ \\
GrA-15268 & MT-375 & AD 371 - AD 380 & $1725 \pm 50$ \\
GrA-15269 & MT-385 & AD 381 - AD 390 & $1675 \pm 50$ \\
GrA-15270 & MT-395 & AD 391 - AD 400 & $1640 \pm 50$ \\
GrA-15273 & MT-405 & AD 401 - AD 410 & $1580 \pm 50$ \\
GrA-15320 & MT-415 & AD 411 - AD 420 & $1660 \pm 50$ \\
GrA-15275 & MT-425 & AD 421 - AD 430 & $1580 \pm 50$ \\
GrA-15276 & MT-435 & AD 431 - AD 440 & $1655 \pm 50$ \\
GrA-15278 & MT-445 & AD 441 - AD 450 & $1595 \pm 50$ \\
GrA-15279 & MT-455 & AD 451 - AD 460 & $1640 \pm 50$ \\
GrA-15280 & MT-465 & AD 461 - AD 470 & $1590 \pm 50$ \\
GrA-15283 & MT-475 & AD 471 - AD 480 & $1645 \pm 50$ \\
GrA-15287 & MT-485 & AD 481 - AD 490 & $1520 \pm 50$ \\
GrA-15289 & MT-495 & AD 491 - AD 500 & $1570 \pm 50$ \\
GrA-15291 & MT-505 & AD 501 - AD 510 & $1555 \pm 50$ \\
GrA-24950 & MT-515 & AD 511 - AD 520 & $1480 \pm 50$ \\
GrA-15293 & MT-525 & AD 521 - AD 530 & $1535 \pm 50$ \\
GrA-15294 & MT-535 & AD 531 - AD 540 & $1520 \pm 50$ \\
GrA-15296 & MT-545 & AD 541 - AD 550 & $1445 \pm 50$ \\
GrA-15298 & MT-555 & AD 551 - AD 560 & $1480 \pm 50$ \\
GrA-15299 & MT-565 & AD 561 - AD 570 & $1480 \pm 50$ \\
GrA-15301 & MT-575 & AD 571 - AD 580 & $1385 \pm 50$ \\
GrA-15302 & MT-585 & AD 581 - AD 590 & $1540 \pm 50$ \\
GrA-15303 & MT-595 & AD 591 - AD 600 & $1485 \pm 50$ \\
GrA-15304 & MT-605 & AD 601 - AD 610 & $1495 \pm 50$ \\
GrA-15306 & MT-615 & AD 611 - AD 620 & $1490 \pm 50$ \\
GrA-15307 & MT-625 & AD 621 - AD 630 & $1350 \pm 50$ \\
\hline
\end{tabular}

Table 4 Results of ${ }^{14} \mathrm{C}$ measurements (conventional) for the $\mathrm{AH} 1$ series

\begin{tabular}{lllll}
\hline Lab. code & Sample name & Tree-ring age & $\delta^{13} \mathrm{C}(\%)$ & ${ }^{14} \mathrm{C}$ age $(\mathrm{BP})$ \\
\hline GrN-25080 & AH1-696 & AD 692-AD 701 & -26.35 & $1287 \pm 25$ \\
GrN-25081 & AH1-706 & AD 702-AD 711 & -26.18 & $1284 \pm 25$ \\
GrN-25082 & AH1-716 & AD 712 - AD 721 & -26.42 & $1255 \pm 25$ \\
GrN-25083 & AH1-726 & AD 722 - AD 731 & -26.85 & $1287 \pm 26$ \\
GrN-25084 & AH1-736 & AD 732 - AD 741 & -26.57 & $1286 \pm 23$ \\
GrN-25085 & AH1-746 & AD 742 - AD 751 & -26.37 & $1313 \pm 26$ \\
GrN-25086 & AH1-756 & AD 752 - AD 761 & -26.56 & $1317 \pm 26$ \\
GrN-25087 & AH1-766 & AD 762-AD 771 & -26.34 & $1301 \pm 26$ \\
GrN-25088 & AH1-776 & AD 772 - AD 781 & -25.58 & $1255 \pm 43$ \\
GrN-25089 & AH1-786 & AD 782 - AD 791 & -25.70 & $1228 \pm 31$ \\
GrN-25090 & AH1-796 & AD 792 - AD 801 & -25.37 & $1227 \pm 28$ \\
\hline
\end{tabular}


Table 5 Results of ${ }^{14} \mathrm{C}$ measurements (AMS) for the $\mathrm{AH} 3$ series

\begin{tabular}{llll}
\hline Lab. Code & Sample name & Tree-ring age & ${ }^{14}$ C age (BP) \\
\hline GrA-14997 & AH3-665 & AD 661 - AD 670 & $1340 \pm 60$ \\
GrA-14998 & AH3-675 & AD 671 - AD 680 & $1320 \pm 60$ \\
GrA-14999 & AH3-685 & AD 681 - AD 690 & $1250 \pm 60$ \\
GrA-15000 & AH3-695 & AD 691 - AD 700 & $1240 \pm 60$ \\
GrA-15002 & AH3-705 & AD 701 - AD 710 & $1230 \pm 60$ \\
GrA-15003 & AH3-715 & AD 711 - AD 720 & $1250 \pm 60$ \\
GrA-15004 & AH3-725 & AD 721 - AD 730 & $1270 \pm 60$ \\
GrA-15007 & AH3-735 & AD 731 - AD 740 & $1240 \pm 60$ \\
GrA-15008 & AH3-745 & AD 741 - AD 750 & $1280 \pm 60$ \\
GrA-15009 & AH3-755 & AD 751 - AD 760 & $1320 \pm 60$ \\
GrA-15082 & AH3-765 & AD 761 - AD 770 & $1310 \pm 45$ \\
GrA-15084 & AH3-775 & AD 771 - AD 780 & $1225 \pm 45$ \\
GrA-15086 & AH3-785 & AD 781 - AD 790 & $1230 \pm 45$ \\
GrA-15095 & AH3-795 & AD 791 - AD 800 & $1245 \pm 45$ \\
GrA-15139 & AH3-805 & AD 801 - AD 810 & $1215 \pm 40$ \\
GrA-15140 & AH3-815 & AD 811 - AD 820 & $1115 \pm 40$ \\
GrA-15143 & AH3-825 & AD 821 - AD 830 & $1200 \pm 40$ \\
GrA-15144 & AH3-835 & AD 831 - AD 840 & $1210 \pm 40$ \\
GrA-15146 & AH3-845 & AD 841 - AD 850 & $1190 \pm 40$ \\
GrA-15153 & AH3-855 & AD 851 - AD 860 & $1235 \pm 40$ \\
GrA-15150 & AH3-865 & AD 861 - AD 870 & $1225 \pm 40$ \\
GrA-15151 & AH3-875 & AD 871 - AD 880 & $1235 \pm 40$ \\
GrA-15152 & AH3-885 & AD 881 - AD 890 & $1165 \pm 40$ \\
GrA-15155 & AH3-895 & AD 891 - AD 900 & $1185 \pm 40$ \\
\hline & & &
\end{tabular}

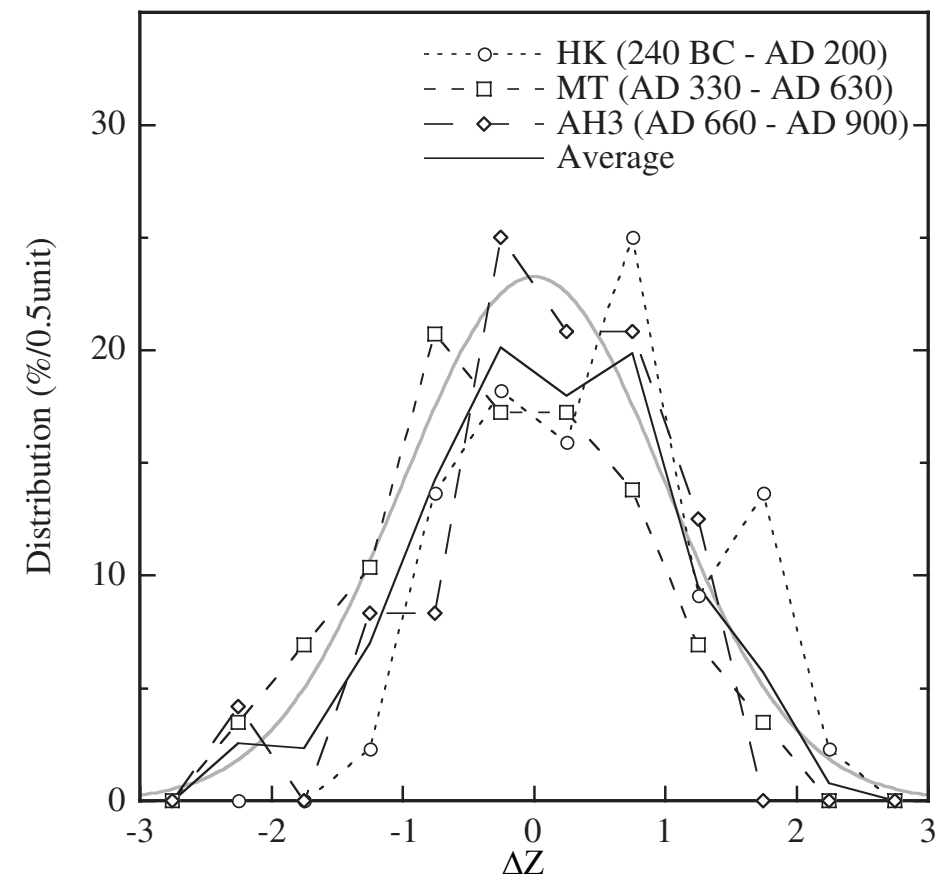

Figure 3 Difference between ${ }^{14} \mathrm{C}$ data for Japanese cedars and INTCAL98 
and 0.16 for $\mathrm{HK}, \mathrm{MT}$ and $\mathrm{AH} 3$, respectively. The data of $\mathrm{AH} 1$ are too small to show a meaningful distribution. If we take a typical error of each determination, the shifts are $18,-10$, and $6{ }^{14} \mathrm{C} \mathrm{yr}$, respectively.

The wiggle-matched date of each specimen is calculated using all the data by comparing with the INTCAL98 calibration curve. The calculated dates are in very good agreement with the dendrochronological dates determined for each specimen. Although it is known that the calculated age should be less influenced by the regional effect (Bronk Ramsey et al. 2001), the observations above also enforce the correctness of using INTCAL98 calibration curve for Japanese wood samples.

The above conclusion is based on the data set of each sample specimen of a rather long period. To search the detailed structure of the regional effect, $50 \mathrm{yr}$ of averages of the differences between the data and INTCAL98 are calculated and plotted in Figure 4. The figure shows the difference is within the $2 \sigma$ uncertainties except for the values around AD 100 to AD 200, indicating absence of regional effect that exceeds $20{ }^{14} \mathrm{C}$ yr in the time scale of 50 calendar yr.

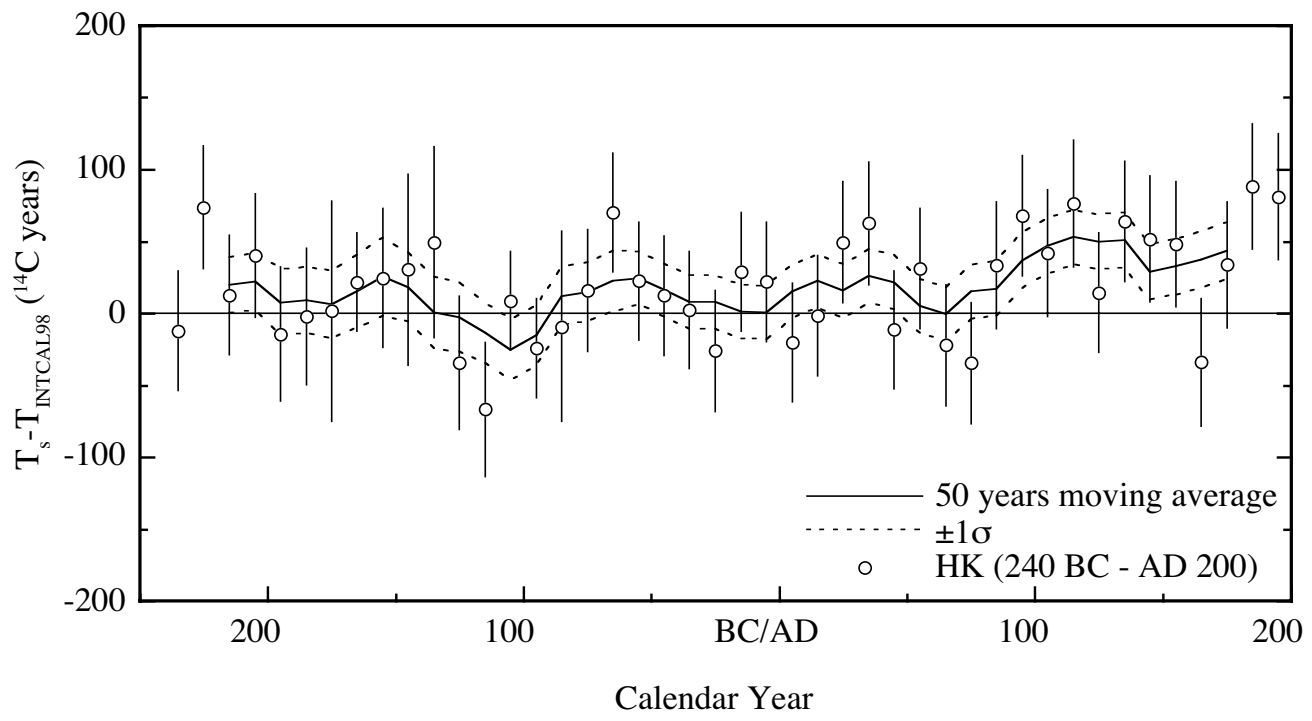

Figure 4 Difference of ${ }^{14} \mathrm{C}$ ages between Japanese cedar and INTCAL98

For the data of AD 100 to AD 200, we possibly observe a regional or local effect. The 50 -yr averages for these periods certainly deviate more than the $2 \sigma$ uncertainties from those of the INTCAL98. At present, we consider 2 possibilities: that the regional effect exists in this period for Japanese islands, or that the effect is only local due to the volcanic activities from a nearby volcano (Mt. Fuji for example) and restricted to the area around the Fuji-Hakone National Park in Japan where the HK sample was taken. We plan to measure another tree-ring sample of the same period but taken from a different area of Japan.

\section{CONCLUSIONS}

From the present study, it is clear that the differences in atmospheric ${ }^{14} \mathrm{C}$ concentrations between Japan and North America or Europe are negligible or small during the period of $270 \mathrm{BC}$ to AD 900, suggesting that there is little disturbance of ${ }^{14} \mathrm{C}$ in the atmosphere caused by the ocean near the Japanese archipelago. This is likely because the air mass moves eastwards at the mid-latitude and 
reaches Japan with little influence of the ocean. However, we found a possible deviation in the period of about $\mathrm{AD} 100$ to $\mathrm{AD} 200$, which requires future investigation.

\section{ACKNOWLEDGMENTS}

We are indebted to Professors Hiroyuki Kitagawa and Toshio Nakamura for useful discussions and comments. J van der Plicht is indebted to the Japan Society of Promotion of Science (S02027) for their support and fellowship. The work is supported by a Grant-in-Aid (No. 09301017) of the Ministry of Education, Science, Culture, and Sports in Japan.

\section{REFERENCES}

Imamura M, Sakamoto M, Shiraishi T, Sahara M, Nakamura T, Mitsutani T, van der Plicht J. 1998. Radiocarbon age calibration for Japanese wood samples: wiggle-matching analysis for a test specimen. In: Evin $\mathrm{J}$, Oberlin C, Daugas JF, Salles JF, editors. Proceedings of the 3rd International Symposium on ${ }^{14} \mathrm{C}$ and $\mathrm{Ar}$ chaeology, Lyon. Revue d'Archeometrie 23:79-82.

Mitsutani T. 2002. Dendrochronology in Japan and its applications to archaeology. Paper presented at the 6th International Conference on Dendrochronology. Quebec, Canada, 22-27 August.

Mook WG, Streurman HJ. 1983. Physical and chemical aspects of radiocarbon dating. In: Mook WG, Waterbolk HT, editors. Proceedings of the 2nd International Symposium on ${ }^{14} \mathrm{C}$ and Archaeology. Groningen: PACT Publishers 8:31-55.

Nara National Cultural Properties Research Institute. 1990. Dendrochronology in Japan. Research Report of the Nara National Cultural Research Institute 48. In Japanese with summary in English.

Ramsey B, van der Plicht J, Weninger B. 2001. "Wiggle matching" radiocarbon dates. Radiocarbon 43(2A): 381-9.

Stuiver M, Reimer PJ, Bard E, Beck JW, Burr GS, Hughen KA, Kromer B, McCormac G, van der Plicht J, Spurk M. 1998. INTCAL98 Radiocarbon Age Calibration, 24,000-0 cal BP. Radiocarbon 40(3):104183.

van der Plicht J, Streurman HJ, Schreuder GR. 1992. A new data acquisition system for the Groningen counters. Radiocarbon 34(3):500-5.

van der Plicht J, Wijma S, Aerts AT, Pertuisot MH, Meijer HA.J. 2000. Status report: The Groningen AMS facility. Nuclear Instruments and Methods, Section B 172(1-4):58-65. 